January 2022

\title{
Impact of Clinical and Cultural Activities on Personal Growth During International Service-Learning
}

\author{
Monique Chabot \\ Widener University - Main Campus, mcchabot@widener.edu \\ Marina Mitchell \\ American International College, marinamitchell@gmail.com \\ Elizabeth Stevens-Nafai \\ stevens.nafai@gmail.com \\ Said Nafai \\ American International College and OT Morocco, said.nafai@otmorocco.org
}

Follow this and additional works at: https://nsuworks.nova.edu/ijahsp

Part of the Medicine and Health Sciences Commons

\section{Recommended Citation}

Chabot M, Mitchell M, Stevens-Nafai E, Nafai S. Impact of Clinical and Cultural Activities on Personal Growth During International Service-Learning. The Internet Journal of Allied Health Sciences and Practice. 2022 Jan 03;20(1), Article 11.

This Manuscript is brought to you for free and open access by the College of Health Care Sciences at NSUWorks. It has been accepted for inclusion in Internet Journal of Allied Health Sciences and Practice by an authorized editor of NSUWorks. For more information, please contact nsuworks@nova.edu. 


\title{
Impact of Clinical and Cultural Activities on Personal Growth During International Service-Learning
}

\begin{abstract}
Purpose: When healthcare students participate in international service-learning experiences, they are exposed to a culture that is different from their own. This exposure, accomplished through cultural and clinical activities, can help to develop their clinical skills and result in personal growth. However, the individual impact of clinical versus cultural activities on personal growth is poorly understood. This study examines the impact on personal growth of clinical activities and cultural activities during international service-learning in occupational therapy students. Methods: Qualitative interviews using a phenomenological approach were utilized to explore the lived experiences of American occupational therapy students who traveled to Morocco. Responses were coded and analyzed to identify general themes on the impact of different clinical and cultural activities. Qualities of impactful experiences were also identified. Results: Participants identified authentic clinical activities that elicited an emotional response and cultural activities that involved full cultural immersion as being most impactful for their personal growth. Conclusion/Recommendations: To support healthcare students' personal growth, international service-learning should be designed to include authentic clinical activities that elicit emotion and reflection and opportunities for full immersion into the culture of the country abroad.
\end{abstract}

\section{Author Bio(s)}

Monique Chabot, OTD, OTR/L, SCEM is an Associate Professor of Occupational Therapy at Widener University in Chester, PA. She leads international service learning experiences to Morocco as faculty chaperone. At the time of travel, she was faculty at Thomas Jefferson University in Philadelphia, PA.

Said Nafai, OTD, OTR/L, CLT is an Associate Professor of Occupational Therapy at American International College in Springfield, MA. He is the founder of OT Morocco and the creator of the international service learning experience to Morocco.

Marina Mitchell, MS, OTR/L was a student at American International College. She currently works for Fox Rehabilitation.

Elizabeth Stevens-Nafai, MS, OTR/L works in school based practice in Worcester, MA. She serves as a fieldwork educator for OT Morocco and the international service learning experiences to Morocco. 


\title{
1IVAHSP \\ The Internet Joumnal of Allied Health Sciences and Practice \\ Dedicated to allied health professional practice and education \\ Vol. 20 No. 1 ISSN 1540-580X
}

\section{Impact of Clinical and Cultural Activities on Personal Growth During International Service-Learning}

\author{
Monique C. Chabot ${ }^{1}$ \\ Said Nafai ${ }^{2}$ \\ Marina Mitchell2 \\ Elizabeth Stevens-Nafai ${ }^{3}$ \\ 1. Thomas Jefferson University \\ 2. American International College \\ 3. School-based Practice \\ United States
}

\begin{abstract}
Purpose: When healthcare students participate in international service-learning experiences, they are exposed to a culture that is different from their own. This exposure, accomplished through cultural and clinical activities, can help to develop their clinical skills and result in personal growth. However, the individual impact of clinical versus cultural activities on personal growth is poorly understood. This study examines the impact on personal growth of clinical activities and cultural activities during international service-learning in occupational therapy students. Methods: Qualitative interviews using a phenomenological approach were utilized to explore the lived experiences of American occupational therapy students who traveled to Morocco. Responses were coded and analyzed to identify general themes on the impact of different clinical and cultural activities. Qualities of impactful experiences were also identified. Results: Participants identified authentic clinical activities that elicited an emotional response and cultural activities that involved full cultural immersion as being most impactful for their personal growth. Conclusion/Recommendations: To support healthcare students' personal growth, international service-learning should be designed to include authentic clinical activities that elicit emotion and reflection and opportunities for full immersion into the culture of the country abroad.
\end{abstract}

Keywords: personal growth, international service-learning, clinical activities, cultural activities 


\section{BACKGROUND}

International service-learning provides healthcare students with educational activities in a foreign country that are tied to a curriculum and provide clinical skills learning in a different cultural setting1. Within occupational therapy education, international service-learning experiences allow students to develop their clinical and interpersonal skills, as well as increase their social awareness. ${ }^{1,2,3,4}$ These experiences are available across all continents and vary in terms of size, duration, and number of settings. The majority introduce students to underserved populations via community-based clinics, residential facilities, and pediatric rehabilitation clinics.5,6,7 Cultural activities may include local shopping, exposure to traditional art forms, civic engagement, and nature activities. ${ }^{8,9}$

Students benefit from their experiences by gaining broader global perspectives and developing a multi-faceted understanding of how occupational therapy is implemented across cultures. ${ }^{4}$ They also experience personal growth linked to increased selfawareness, tolerance, and acceptance of diversity through self-reflection on personal values and beliefs. ${ }^{10,11,12}$ Manifestations of personal growth include the development of personal characteristics such as confidence, flexibility, adaptability, perseverance, autonomy, and calmness in challenging situations. ${ }^{12,13}$ Reflection and skills developed by personal growth are an important part of developing cultural sensitivity, in which healthcare practitioners empathically understand and respond to a client's cultural background, values, and beliefs in order to provide appropriate and relevant care.3,14,15 The ability to provide culturally sensitive care develops with time, exposure, and personal reflection, leading to better client health outcomes. ${ }^{15,16}$ As such, personal growth is considered a positive psychological change that allows healthcare practitioners to better establish rapport and provide clientcentered care.3,17,18

Research within rehabilitation professional pedagogy, such as physical and occupational therapy, focuses primarily on the impact of clinical activities on students' clinical and professional development, finding a positive correlation between clinical exposure and personal growth. ${ }^{6}$ An experience to Morocco for nursing and dentistry students found that personal growth was positively correlated with participation in cultural activities.9,11 Similarly, an international cultural immersion experience in Mexico with licensed occupational therapy practitioners documented a link between participation in cultural activities and increased cultural sensitivity and openness to new cultures. ${ }^{8}$ Still, no study has yet identified the specific cultural activities primarily responsible for influencing personal growth nor compared the respective impact of clinical versus cultural activities. To learn more, we investigated the impact of clinical and cultural activities on personal growth among occupational therapy students during an international service-learning experience to Morocco, with a focus on specifically identifying the most impactful activities and their respective qualities.

\section{METHODS}

A qualitative study was conducted to examine occupational therapy students' perception of the impact of clinical and cultural activities on their personal growth during an occupational therapy service-learning experience to Morocco. This experience was designed and completed with a single service-learning organization with no direct relationship to any academic institution or occupational therapy program. A phenomenological approach was taken to gather common themes and perceptions from the shared experiences of participants. ${ }^{19}$ This was deemed appropriate for this study in order to generalize the impact of clinical and cultural activities on students' personal growth and any common characteristics found to be impactful between types of activities. An online quantitative survey was utilized to gather informed consent, demographic information, and contact information from interested participants to schedule the interview. Institutional Review Board approval was sought and obtained. Informed consent was provided by all participants.

\section{Participants}

The international service-learning experience to Morocco lasted nine to ten days, across five to six different cities in various regions of the country. Students were introduced to a variety of community-based settings that served clients of all ages with various health conditions. The experience was open to all interested occupational therapy students enrolled full time at their respective institutions and in good academic standing at the time of travel. Participation in the experience was voluntary and extra-curricular to their education, save for five students from one institution who chose to utilize the experience as a community-based fieldwork placement.

All occupational therapy students $(n=80)$ who traveled to Morocco during one of five service-learning experiences between 2017 and 2018 were invited to participate. On any given experience, the number of traveling students ranged from eight to eighteen, with an average of 14 students per experience. The service-learning organization provided emails of all past travelers as potential study participants; they were invited via email with a link to the online demographic survey. Twenty-two participants provided informed consent, completed the demographic survey, and provided contact information. Seventeen participants completed the interview process. 
All participants ( $n=17$ ) were occupational therapy students in an accredited occupational therapy program on the east coast of the United States. At the time of travel, $18.75 \%$ of participants were first year students, $68.75 \%$ were second year students, and $12.50 \%$ were third year students. All participants identified as female with an age range of 22-37 years old (mean 26.38). They predominantly identified as Caucasian (62.5\%); other ethnicities identified included African-American (12.50\%), Asian (18.75\%), and Other (6.25\%). Prior to Morocco, most participants had traveled internationally (87.5\%), mainly to European countries (25\%) for vacation-related reasons $(65 \%)$.

The itinerary of the service-learning experience was organized by a Moroccan-American occupational therapist who ran the service-learning experience and had direct connections to the local community organizations. This clinician led each experience in conjunction with faculty chaperones. The daily agenda was split equally between clinical and cultural activities to provide exposure to clinical needs of the population and authentic cultural immersion. Researchers surmised that while clinical activities were naturally necessary for healthcare students to develop professional skills, participation in authentic cultural activities would also be valuable.

Prior to travel, all students participated in four pre-experience educational sessions covering travel health, culture, language, and pre-departure preparation. Depending on the requirements of their home institutions, this was provided either in person during one-hour long meetings or asynchronously via email. All education materials were provided by the service-learning organization in order to prepare students for the clinical and cultural activities and provide information on culturally appropriate behaviors and general logistics.

The aim of all activities was to provide opportunities to practice burgeoning clinical skills with underserved populations and to provide authentic exposure to Moroccan culture. Clinical activities took place in traditional healthcare settings for patients with physical or mental health disabilities, community centers for adults and children with disabilities, a home for women recovering from cancer, nursing homes, schools for children with disabilities, and orphanages. The students provided interventions to affect mental health, social and leisure activity participation, and traditional physical disability rehabilitation. The cultural activities included shopping in traditional markets, camel rides, music and dance shows, tours of historical and religious sites and cities, and visits to Moroccan families in their homes. Further exposure to Moroccan culture also came incidentally through daily interactions with people and while following the Moroccan flow of the day regarding mealtimes and downtime for prayer throughout the day.

\section{Procedure}

An interview guide was developed based on a literature review, and interviews adhered to a phenomenological approach to explore the lived experiences of the participants. ${ }^{19}$ Semi-structured interviews were conducted to capture student perceptions and generalize the characteristics of the impactful clinical and cultural activities on participants' personal growth. Participants first answered demographic questions through an online survey and provided contact information to volunteer for the interview. Questions regarding previous travel and exposure to different cultures were treated as demographic data. Table 1 contains the quantitative survey.

Table 1. Quantitative Survey

1. What year in your OT program are you? If you have graduated, what year did you graduate OT school?

2. Which institution do/did you attend?

3. What is your age?

4. Which ethnicity do you identify with?

5 . Which gender identity do you identify with?

6. What year in your OT program were you when you traveled to Morocco?

7. Have you traveled internationally before? If yes, where and for what purpose?

8. For each item identified below, circle the number to the right that best fit your judgment of its quality. Use the rating scale to select the quality number.

1: Disagree, 5: Agree

\begin{tabular}{|l|l|l|l|l|l|l|}
\hline Item 8.1 & $\begin{array}{l}\text { I found value in my participation on this trip within the context of my } \\
\text { occupational therapy education. }\end{array}$ & 1 & 2 & 3 & 4 & 5 \\
\hline Item 8.2 & $\begin{array}{l}\text { I have a better understanding of my role as an occupational therapist on an } \\
\text { international platform. }\end{array}$ & 1 & 2 & 3 & 4 & 5 \\
\hline Item 8.3 & $\begin{array}{l}\text { The cultural/tourist experiences have assisted me in developing my } \\
\text { professional identity. }\end{array}$ & 1 & 2 & 3 & 4 & 5 \\
\hline
\end{tabular}




\begin{tabular}{|l|l|l|l|l|l|l|}
\hline Item 8.4 & $\begin{array}{l}\text { The clinical experiences enhanced my understanding of how culture } \\
\text { impacts occupational performance. }\end{array}$ & 1 & 2 & 3 & 4 & 5 \\
\hline Item 8.5 & $\begin{array}{l}\text { The cultural/tourist activities enhanced my understanding of how culture } \\
\text { impacts occupational performance. }\end{array}$ & 1 & 2 & 3 & 4 & 5 \\
\hline Item 8.6 & $\begin{array}{l}\text { The clinical experiences have assisted me in developing my professional } \\
\text { identity. }\end{array}$ & 1 & 2 & 3 & 4 & 5 \\
\hline Item 8.7 & $\begin{array}{l}\text { I feel the clinical experiences enhanced my ability to deliver culturally } \\
\text { sensitive care. }\end{array}$ & 1 & 2 & 3 & 4 & 5 \\
\hline Item 8.8 & $\begin{array}{l}\text { I feel the cultural/tourist experiences enhanced my ability to deliver } \\
\text { culturally sensitive care. }\end{array}$ & 1 & 2 & 3 & 4 & 5 \\
\hline Item 8.9 & $\begin{array}{l}\text { Prior to this experience, rank the level of your comfort working with people } \\
\text { of other cultures as a future OT clinician. }\end{array}$ & 1 & 2 & 3 & 4 & 5 \\
\hline Item 8.10 & $\begin{array}{l}\text { After this experience, rank the level of your comfort working with people of } \\
\text { other cultures as a future OT clinician }\end{array}$ & 1 & 2 & 3 & 4 & 5 \\
\hline
\end{tabular}

9. Rank the amount of each experience that should be present on future trips:

\begin{tabular}{|l|l|l|l|l|}
\hline Item 9.1 & Cultural/Tourist Experiences & More & The Same & Less \\
\hline Item 9.2 & Clinical Experiences & More & The Same & Less \\
\hline
\end{tabular}

Within the interview itself, questions re-established demographic information through deeper inquiries into past exposure to other cultures before asking the participant to identify and reflect on the personal impact of the clinical and cultural activities in Morocco. The intent of the questions was to capture a holistic understanding of the impact of the entire experience on participants and to elicit reflection, which is a key component to personal growth during or after an international service-learning experience. ${ }^{21}$ Other interview questions delved into other aspects of the experience, specifically on professional identity development, culturally sensitive care delivery, program improvement, and occupational therapy-specific skills related to identification of cultural impacts on everyday life. Table 2 contains the interview guide.

Table 2. Qualitative Interview Questions

1. Have you traveled abroad? If so, where have you traveled abroad before? Tell me how those past experiences influenced your participation in this experience.

2. Tell me how this experience to Morocco has impacted your viewpoint on culture and occupation.

3. Tell me about the impact this experience has had on your educational journey.

4. Think back on the entire experience and tell me what lessons you took away from the trip.

5. Tell me about which experiences (either clinical or cultural/tourist) had a greater personal impact on you and why. How did these impact you personally?

6. Tell me which experiences (clinical or cultural/tourist) had a greater professional impact on you and why. How did these impact you professionally?

7. Tell me about your perception regarding your ability to provide culturally sensitive care in your future practice. How has this changed, if at all, since before the trip? What experiences do you feel are responsible for any changes?

8. Which specific experiences do you wish there was more of and why?

9. Which specific experiences do you wish there was less of and why?

10. What suggestions do you have to improve future trips to increase your understanding of culture and healthcare provision or better prepare you for the experience in general?

The questions in the interview guide were reviewed by two other investigators and revised based on suggestions from the investigators. Interviewers piloted the interview guide to ensure consistency between interview styles and ensure face validity. ${ }^{19}$ Participants were not interviewed by someone connected with their educational institution nor their specific experience to avoid potential response bias. ${ }^{22}$ Face-to-face interviews were scheduled per participant availability and completed in approximately 30 minutes via teleconference technology. The interviews were recorded and transcribed verbatim. All records were stored in encrypted password-protected files on an encrypted password-protected network via a study ID. 


\section{Data Analysis}

After one investigator transcribed the interviews, the transcripts were verified by a second investigator to ensure accuracy. Transcripts were independently coded by four members of the research team. A fifth investigator created a code book from a compilation of the individual codes; the draft code book was reviewed by the other members of the research team. In order to reduce potential bias through triangulation, the research team reached consensus on the code book. ${ }^{19} \mathrm{~A}$ second individual coding of the transcripts was completed by five members of the research team. Consensus was reached on the final themes through discussion of the team members. In the quantitative survey, responses to Items 1-7 were used as demographic data. In the interview guide, responses to Items 4 and 5 were analyzed as these questions focused specifically on personal growth by requesting identification of specific clinical and cultural activities that caused student reflection, not otherwise linked to clinical skills or cultural sensitivity.

\section{RESULTS}

\section{Clinical Activities on Personal Growth}

Participants noted a variety of impactful clinical activities along with general emotions, both positive and negative, in response to clinical activities. The emotional reactions to these visits were identified by the participants as contributing to personal growth. The three themes identified were "Authentic Clinical Experiences," "Positive Emotions," and "Negative Emotions."

\section{Theme 1: Authentic Clinical Experiences}

The service-learning experience required participants to participate in many different clinical activities across the lifespan and population. These activities caused participants to pause and reflect on their preconceived notions regarding resource and support availability within different cultures. When asked to consider the impact of any specific activities on personal growth, participants identified orphanages to be the most impactful, followed by a specific cerebral palsy clinic in an underserved and remote mountain region, one of the few nursing homes in the country, schools, and a home for women receiving treatment for cancer. In the identification of these specific activities, two subthemes were present: "Role of Site in the Culture," and "Resource Availability."

\section{Subtheme 1: Role of Site in Culture}

Participants noted the unique role of specific sites within the greater Moroccan culture. This was particularly notable for the orphanage, school for children with disabilities, and women's shelters, some of which were the result of grassroots efforts of women. Students reflected that orphanages are not a typical part of American culture, but they play an integral role in Morocco to care for abandoned children with and without disabilities. The power of safe spaces within the greater culture to care for vulnerable populations was noted, especially the ability to provide care, personal support, advocacy, and a sense of community. Participants reported reflecting on the differences in Moroccan and American culture, their own values and beliefs regarding care for vulnerable populations, and the differences in organizational structure due to cultural and local political influences. Of all the settings identified under this theme, orphanages were mentioned most often. Several settings shared the common theme of being founded by women, leading to the next most common reflection regarding participants observing the empowerment of women to affect change within their communities. The following statement represents this theme:

The experiences where we were able to visit those orphanages or woman shelters, I just thought it was unique how women with the role they played in that culture. I thought it was interesting how they were able to find safe havens for themselves and uplift each other just by unifying and getting together.

\section{Subtheme 2: Resource Availability}

This theme appeared most often in reference to the orphanages, the rural community cerebral palsy clinic, and the nursing home. All three of these locations served underserved populations with limited resources by providing care in innovative ways with any available resource. Participants reflected on the importance of resources and on their growth in awareness of the disparity of resources internationally. They also mentioned an awareness of the impact that donations could have on a community, as all trips involved bringing supplies and items to be used as part of therapeutic interventions. The students spoke about the overwhelming positive reaction to these donations and the assistance they provided, expressing surprise about people's need for even the smallest materials that they contributed. Along with physical resources, participants expressed surprise about people's health literacy and about the questions they were asked regarding a child's prognosis or understanding of the health condition. The participants also noted taking for granted the resources available in the United States to support people with disabilities, ranging from availability of equipment, education to understand health information, and legislation around accessibility. All of these reflections revealed how participants became more aware of their potential future impact on people's lives as clinicians. The following statement represents this theme: 
So, we went to the clinics in the really rural areas and we went to the orphanages where we donated things, and we saw the impact we were having on people's lives there.

\section{Theme 2: Positive Emotions}

Within this theme, participants noted general positive emotions in response to clinical experience exposure and its impact on them personally, specifically humility and development of compassion. The words humility and compassion appeared most often when they reflected on their clinical activities and personal growth. These words were typically directed to some form of positive interpersonal interaction, such as a one-on-one interaction with clients, residents, or caregivers, that took place on a clinical site visit. Participants also mentioned that they felt grateful for the availability of resources in the United States as compared to Morocco. They noted sense of satisfaction with being able to provide services and a positive and supportive experience to others within the clinical settings. In general, participants enjoyed being in the clinics to provide care with their developing skills and remarked positively on the opportunity. Being in the clinic caused participants to find satisfaction within their choice of career as future occupational therapists. The following statement represents this theme:

So the compassion piece. Just to be more compassionate towards people.

\section{Theme 3: Negative Emotions}

While there was a distinct theme of positive emotions, participants also noted that they had difficulty processing some of the activities. The emotions themselves were not necessarily negative, but some students expressed that the clinical site visits caused them to feel sad. The specific sites that elicited this response had a similar characteristic of involving care for individuals who had been abandoned, such as the orphanage and nursing home. It is important to note that nursing homes are not considered a typical part of caring for older adults in Moroccan culture, as most families care for their elderly members; those who live in nursing homes have no family available to care them. Participants responded to their experiences in these sites with concern, such as opportunity for normal childhood development for those living in orphanages and about a lack of access to various meaningful activities, and with frustration at the lack of follow through with clinical recommendations. Participants felt challenged by these clinical activities and required support to process the resulting emotions. Processing with faculty chaperones often led to discussion and reflection on advocacy ideas to help the clients residing in these facilities. The following statement reflects this theme:

The orphanage was a big one, that was, that was really hard to see... So I think that was really impactful just imagining how those kids are going to grow up, just how occupational deprivation and social deprivation really affect how they grow up.

\section{Cultural Activities on Personal Growth}

Participants identified several themes regarding the impact of cultural activities on their personal growth. These themes were "Being Abroad," "Religion," and "Age of Culture." In general, being abroad and immersed in a different culture and climate led participants to reflect on their personal values and the culture to which they were accustomed. Aside from the theme of "Religion" and surfing lessons in "Being Abroad," participants did not identify specific cultural activities when reflecting on personal growth.

\section{Theme 1: Being Abroad}

Participants had various levels of past experiences being abroad in terms of frequency and the general cultural regions visited. Several participants noted the novelty of being abroad and authenticity of activities as important for their personal growth. Others noted the cultural activities forced them out of their comfort zones and provided them with the opportunity to try new experiences. The experience of seeing different landscapes was noted, along with riding in the private bus for long durations while navigating cities, beaches, and rural/remote mountain areas. In addition to topography, some participants remarked on the weather as they never experienced a dry, desert heat before, remarking they grew in awareness of global climate differences. Participants stated being present in the moment to reflect on their entire experience of being abroad helped them appreciate the country and culture. The following statement represents this theme:

Well the clinical experiences like I said I think just boosted my confidence but my favorite experience um, that was more like touristy was surfing.... And it really just ... taught me to like try new things, and step out of my comfort zone, which like I said, I never went to another country before.

\section{Theme 2: Religion}

Participants commented on the role of religion in the daily lives of Moroccans and observations regarding spirituality, religion, and its relation to everyday actions. Many expressed that they had little understanding of any religion prior to the trip, and found that their personal understanding of the role of spirituality in people's lives grew through experiencing the role of Islam within Moroccan 
culture. Students also expressed surprise at the infusion of Muslim values into everyday life compared to the secularism of the United States. Participants also reported being surprised by the level of religious tolerance they encountered. This awareness of Moroccan spiritual life was achieved both through visits to a mosque and being immersed authentic Moroccan culture, which is influenced by Muslim values. In particular, several participants expressed awe and admiration at the beauty of the mosque and reflected on following Muslim customs inside the mosque, out of respect for the people. One participant noted bringing a newfound understanding of Islam back to the United States to promote tolerance. The following statement represents this theme:

I'm a Christian and I really appreciated the appreciation or the respect that the Muslims and Jews had for each other. And even though it's a Muslim, predominately Muslim country, I just I've never been in a place where I felt more at peace spiritually.

\section{Theme 3: Age of Culture}

Several participants observed and commented on the long history of Moroccan culture, specifically as it contrasts with the age of American culture. They attributed qualities such as "richer" to the age of the culture and grew in appreciation for the durability of a culture, as well as the depth and strength that tradition may hold for people. Students noted how their experiences helped increase their respect humanity as a whole and their appreciation for historical development from ancient to modern times. The following statement represents this theme:

So for tourism, it was really cool to be in such an ancient culture and like when we were in Fez like recognizing how not only like, young our country and culture is. But also just like, how much larger the world is and how, like, things have been going on for thousands and thousands of years in this place.... But also gives you a lot of respect for humanity and like where we've come from.

\section{DISCUSSION}

This study examined the effect of clinical and cultural activities during an international service-learning experience to Morocco on occupational therapy students' personal growth. In general, participants identified a variety of clinical and cultural activities that impacted them on a personal level or led to the development of skills, such as flexibility, adaptability, empathy, and calm under pressure. No singular activity or category is prominent as most impactful; rather the qualities of being authentic and causing reflection on the part of the student appears to be the impactful aspect of any clinical or cultural activity. For many, the simple act of being abroad and placed in different clinical and cultural situations that required them to reflect on their own emotions and reactions to the sites in addition to their values, beliefs, and privilege was the contributing experience to personal growth. The fact that both clinical and cultural activities caused participants to reflect and process emotions and to comment on personal growth post-experience supports findings from Knightbridge and Sanders et al., who noted the importance of reflection on experiences during personal growth development. ${ }^{13,20} \mathrm{In}$ fact, being in a context that creates dissonance with our values and beliefs and then processing the information personally is a key component to personal growth per Kiely. ${ }^{21}$ This method of achieving personal growth is also supported by the theory on transformational learning, which purports students use their experiences to gain awareness of themselves and others through reflection on their beliefs, assumptions, and biases. ${ }^{23}$ For the occupational students who went to Morocco, this dissonance and transformational learning was achieved through their participation in a selection of authentic activities that emotionally challenged them.

Students indicated that the most impactful clinical activities involved authentically serving underserved communities in need of physical resources and assistance in situations that differed from American service provision. In particular, clinical activities that elicited strong emotional responses or resource provision in the form of interventions, education, or physical resources made the most impact on students. It was expected and demonstrated in the interviews that volunteering and practicing clinical skills would elicit positive emotions. Interestingly, participants noted feeling challenged and uncomfortable during the clinical activities in situations involving abandonment. This challenge and discomfort are not uncommon during international service-learning experiences and contributes to the required reflection necessary for personal growth, as seen in our data and other studies. ${ }^{12,21,23}$ Additionally, the awareness of privilege, growth in interpersonal skills, and increase in altruism present in our data confirms the findings of other studies examining the impact of clinical activities on personal growth during international service learning in underserved communities. $6,11,12$

Cultural activities appear to have also played a role with personal growth. No particular activity was identified beyond the common theme of the activities being authentic and immersive in the full local culture. Religion being a prevalent theme is not surprising given the prominent role of Islam in Morocco as the dominant religion; for most participants, this was a different experience, having only been exposed to Western Christian cultures. General authentic immersion as a cause of personal growth aligns with other 
international service-learning studies to Morocco and Mexico, where a positive correlation between general cultural exposure and activities and personal growth was reported.8,9,11

Ultimately, our findings reveal that, regardless of the specific clinical or cultural activity, the international service-learning experience in Morocco increased awareness of resource disparities among communities. Participants also developed empathy, compassion, and tolerance for different values, faiths, and ways of living along with a greater desire to serve. Participants noted increased flexibility, confidence, and ability to remain calm in quickly changing situations. All of these qualities are considered personal growth. ${ }^{10}$ The development of these skills was also noted in studies on other international service-learning experiences. ${ }^{12,13}$ Most of these characteristics were mentioned in reference to clinical activities, however some participants noted them in reference to the entire experience as a whole. This suggests that participants more readily identified personal growth characteristics in reference to their growth as future occupational therapists. However, it does not discount the contribution of the cultural activities on their personal growth as human beings.

\section{Limitations}

Limitations include a small sample size. While saturation was reached, it was a convenience and volunteer sample. ${ }^{24}$ This study also describes the experiences from the same service-learning program with the same organization, and all participants were female, which may have resulted in gendered patterns. All participants were studying occupational therapy, meaning the interpretation of their experiences could be influenced by that particular professional culture and lens within the rehabilitation professions. Findings should be applied to other rehabilitation or healthcare professions with caution. Also, while the basic experiences were the same, there were minor variations in activities between different groups and years.

\section{Implications}

International service-learning experiences are becoming popular in many different healthcare profession programs. This study provides information into the types of activities and the personal impact of those activities on traveling students that could be useful to assist other programs in planning international service-learning experiences. Personal growth develops cultural sensitivity and respect for diversity, important qualities for any healthcare practitioner. Our study shows that international service learning experiences can play a role in developing healthcare student's personal and professional development. International servicelearning experiences should include authentic clinical activities designed to elicit personal reflection and emotions, both positive and negative. Other characteristics to consider include authentic immersion in a culture that allows students to experience the landscape and rhythms of another country.

\section{CONCLUSION}

Occupational therapy students reported that an international service-learning experience to Morocco caused them to reflect on their values, beliefs, and American culture. Being abroad and gaining exposure to a different culture, in addition to immersion in authentic clinical activities, especially those that involved care for people who had been abandoned, elicited emotions that required processing. In interviews, students reported personal growth in awareness of others' cultures, their role in supporting people, and a general broadening of their view of the world as a result of these reflective experiences. The interviews also revealed that both clinical and cultural activities caused reflection as long as they were authentic to the culture, and clinical activities that included stark difference from their own culture caused the most amount of reflection. Allied health academic programs should consider intentionally exposing students on international service learning experiences to authentic clinical and cultural activities that cause reflection in order to provide an opportunity for personal growth, which will lead to the development of culturally sensitive care.

\section{REFERENCES}

1. Cipriani J. Integration of international service learning in developing countries within occupational therapy education: Process and implications. Occup Ther Health Care. 2017; 31(1): 61-71.

2. Aldrich RM, Grajo LC. International educational interactions and students' critical consciousness: A pilot study. Am J Occup Ther. 2017; 71(5): 7105230020p1-7105230020p10.

3. Hansen AMW, Muñoz J, Crist PA, Gupta, J, Ideishi RI, Primeau LA. Service learning: Meaningful, community-centered professional skill development for occupational therapy students. Occup Ther Health Care. 2007; 21(1/2): 25-49.

4. Humbert TK, Burket A, Deveney R, Kennedy K. Occupational therapy students' perspectives regarding international cross-cultural experiences. Aust Occup Ther J. 2012; 59(3): 225-234.

5. Cabatan MCC, Grajo LC. Internationalization in an occupational therapy curriculum: A Philippine-American pilot collaboration. Am J Occup Ther. 2017; 71(6): 7106165010p1-7106165010p9.

6. Hall B, Lorenzo A, Mozolic-Staunton B, Matte D. Evaluation of international service learning model of health promotion in a developing country. Int J Work-Integr. 2018;19(4): 399-412. 
7. Johnson AMJ, Howell DM. International service learning and interprofessional education in Ecuador: Findings from a phenomenology study with students from four professions. J Interprof Care. 2017;31(2): 623245-254.

8. Crowe T, Sanchez V, Weber A, Murtagh A. The influence of a Mexican cultural immersion experience on personal and professional healthcare practices. Occup Ther Int. 2016; 23(4): 318-327.

9. Kaddoura M, Puri A, Dominick CA. International academic service learning: Lessons learned from students' travel experiences of diverse cultural and health care practices in Morocco. J Nurs Educ. 2014; 53(1): 45-47.

10. Meyers SA. Service learning as an opportunity for personal and social transformation. Int J Learn High Educ. 2009; 21(3): 373-381.

11. Puri A, Kaddoura M, Dominick C. Student perception of travel service learning experience in Morocco. J Dent Hyg. 2013; 87(4): 235-243.

12. Sim I, Mackenzie L. Graduate perspectives of fieldwork placements in developing countries: Contributions to occupational therapy practice. Aust Occup Ther J. 2016; 63: 244-256.

13. Knightbridge $L$. Experiential learning on an alternative practice education placement: Student reflections on entry-level competency, personal growth, and future practice. Br J Occup Ther. 2014; 77(9): 438-446.

14. Laszloffy T, Habekost J. Using experiential tasks to enhance cultural sensitivity among MFT trainees. J Marital Fam Ther. 2010; 36(3): 333-346.

15. Schell B, Gillen G. Willard and Spackman's occupational therapy. 13th ed. Philadelphia (PA): Wolters Kluwer; 2019.

16. Darawsheh W, Chard G, Eklund M. The challenge of cultural competency in the multicultural 21st century: A conceptual model to guide occupational therapy practice. Open J Occup Ther. 2015; 3(2).

17. Williams IC, Anderson WP, Lopez-Baez SI. Personal growth attributed by nursing students to a diversity class. Nurs Educ Perspect. 2018; 39(4): 235-237.

18. Melton J, Wolters Kluwer Taylor RR. Therapeutic use of self: A model of the intentional relationship. Duncan, EAS, editor. Philadelphia (PA): Elsevier; 2009.

19. Creswell JW, Poth CN. Qualitative inquiry \& research design; Choosing among five approaches. 4th ed. Thousand Oaks (CA): SAGE; 2018.

20. Sanders MJ, Van Oss T, McGeary S. Analyzing reflections in service learning to promote personal growth and community self-efficacy. J Exp Educ. 2016; 39(1): 73-88.

21. Kiely RA. Transformative learning model for service-learning: A longitudinal case study. The Mich J Commun Service Learn. 2005;12(1): 5-22.

22. Leedy PD, Omrod JE. Practical research: Planning and design. 11th ed. New York: Pearson; (2016).

23. van Rensburg EJ, Du Toit SHJ. The value of a rural service learning experience for final year undergraduate occupational therapy students. S Afr J Occup Ther. 2916; 46(1): 9-14.

24. Saunders B, Sim J, Kingstone T, Baker S, Waterfield J, Bartlam B, Burroughs H, Jinks C. Saturation in qualitative research: Exploring its conceptualization and operationalization. Qual Quant. 2018; 52(4): 1893-1907. 